Holger Boerner is sympathetic, opposition within his ruling Social Democratic Party could scupper the scheme. Last weekend, however, Herr Boerner went to his local party for a vote of confidence in his leadership. His mandate as premier of North Hesse was supported, but opposition to the reprocessing plant together with a plan to extend Frankfurt airport was voiced. The likely outcome now is that the reprocessing plant will goahead but local opinion will be firmly divided.

Meanwhile, the local inhabitants of Gorleben have reopened discussion on whether a high-level waste storage facility should be built in the area. At a public meeting in May, several objections to the technical feasibility of the facility were aired: the salt domes are not covered by a layer of clay, they are in contact with ground water in some places, the region may not be as geologically stable as originally thought and natural gas is extracted from the eastern section of the domes in East Germany. Nevertheless, the federal government seems convinced that the Gorleben salt domes offer the best site within West Germany and has said that, even if conditions are not ideal, problems can be overcome by tailoring the waste to suit the geological formation. The government is still committed to an operational storage facility by the $1990 \mathrm{~s}$ and Gorleben still looks like the best option.

Judy Redfearn

\section{European environment Win some, lose some}

\section{Luxembourg}

Environment ministers of the European Community are in the throes of attempting to draw up regulations on the discharge of noxious substances, outlined in the 1976 directive ENV 131. On 11 June, they again came within a hair's breadth of agreement on the seemingly intractable problem of common standards for the discharge of mercury into the aquatic environment. But one outstanding issue remains.

The United Kingdom is continuing to defend its right to apply qualitative objectives for the discharge of mercury from both old and new plants, while Italy and France insist that limiting values should be obligatory for assessing pollution from new plants. The British, it is maintained, are defending a point of principle while their continental partners are protecting their commercial interests. Nevertheless, British officials point out that the Italians, for instance, would find it hard to enforce the proposed maximum values. It is hoped that the disagreement can be resolved within the next three months.

There was further agonizing about the council's decision to postpone the adoption of the so-called Seveso directive on the prevention of major industrial accidents. The French have held up agreement, pleading that the new government

\section{Water works for the Cuna villagers}

\section{Panama}

For the Cuna indians of Panama progress still means hard physical work. But as a result, the inhabitants of the whole Cuna village can now enjoy clean running water.

The Cunas are colourful tribes of interbred indians who live in palm and bamboo huts on the beautiful San Blas islands - a cluster of over 360 small coral islands off Panama's Caribbean coast. The location allows an almost completely autonomous existence.

The island village of Ticantiki, with its 900 inhabitants, is situated on Devil Cays, only 600 yards from the mainland. It is this proximity to the mainland that has allowed fresh water to be piped under the sea to the island.

A new dam has recently been built up in the hills of the mainland as part of a government project involving the labour of the local indians. In indian terms, the dam is three hours' walk through the jungle from the coast. From the dam, fresh water flows through plastic piping down to the island at a rate of 60 gallons per minute.

The building of a water filter has been left entirely to the indians. The filter is situated a half-hour's walk from the coast, about 2 miles. The shell of the filter is made of reinforced concrete and comprises two bins, each about $8 \mathrm{ft}$ square and $6 \mathrm{ft}$ deep. Carefully graded stones are being used to fill the bins and provide the filter surface. Water is sprinkled from overhead through holes in the plastic piping. The filter, though simple in concept, is effective. When it is finished the indians hope to be able to increase the water flow to 80-90 gallons per minute. forest do you find enough stones for a filter of this size? The answer is, at the mouth of the river. Here, children help in the work by grading stones. The men of the village carry the stones up to the filter in sacks suspended from a pole on their shoulder. This load weighs about 50 kilos, yet these tough, stocky indians stride through the jungle as though it were no more than a sack of cotton.

The congress of the village dictates that any able-bodied man who does not carry up a load should pay $\$ 5$ a day to the community. For a culture that lives by fishing, tending plantations and, increasingly tourism, this is a large sum of money.

And the next project for this ambitious little village? To pipe their fresh water to every household.
But one may ask, where in a tropical has not had time to adopt a fresh policy, but hinting that the Mitterrand regime will be more sympathetic than its predecessor to the outstanding problem of transfrontier notification.

Another subject for debate is the threat to the ozone layer posed by chlorofluorocarbons (CFCs 11 and 12). At the end of this year, the European Community is due to review its commitment to reduce the use of these materials in aerosols to 30 per cent of 1976 levels. The commission's report is unlikely to satisfy either side in the dispute.

Although sales of CFCs 11 and 12 as aerosol propellants fell in 1980 to 28.2 per cent of 1976 levels and are expected to drop to 35 per cent this year, sales for other uses such as refrigeration and plastic foam have risen by 34.7 per cent. The commission's report implies that the situation is well in hand, but favours reducing the production of CFCs for uses other than in aerosols. Negotiations are also to be pursued within the framework of the United Nations Environmental Programme and the Overseas Environmental Council for Development. The council seemed content to assume that, even if the ozone layer is being destroyed at an annual rate of 5-7 per cent current measures are adequate. Even so, the Community appears to be taking a daring step; there is nothing like a consensus among its members that the present restrictions are necessary.

Surprisingly, the United Kingdom is pushing for stringent Community restrictions on lead pollution, on the lines recently adopted in Britain, which would mean a lowering of the lead level in petrol from 0.4 to 0.15 grammes per litre. West Germany and Denmark will be enforcing this limit, and it now seems likely that the Commission's 1976 proposed directive on the permissible level of lead in air will also be taken off the shelf. The council has agreed in principle to endorse an environmental standard of 0.2 milligrammes per cubic metre of air, and has directed that the developer should shoulder the costs of the assessment, that the information should be publicly available and that there should be consultations with neighbouring states. However, 130 reservations were tabled against the directive at the beginning of the council meeting.

With an air of embarrassed pride, the ministers also announced agreement on two measures designed to prevent further disasters similar to that of the Amoco Cadiz - drawing up a compendium of the properties of hydrocarbons and a list of oilfighting equipment in the Community. The more important proposal to keep a register of oil tankers most at risk was resisted by the Greeks and passed on for consideration by the transport ministers. The two proposals agreed are the only measures produced since the European Community announced its crusade against oil tanker disasters following the 1978 Amoco Cadiz shipwreck. 